\title{
Plasma-Electrolysis of Dinitrophenol in Gas-Liquid Boundary and Interpretation Using Molecular Orbital Theory
}

\section{Hiroshi Okawa ${ }^{1 *}$, Hiroki Kuroda ${ }^{1}$, Keiko Hirayama-Katayama², Shin-Ichiro Kojima ${ }^{3}$, Tetsuya Akitsu²}

\author{
${ }^{1}$ Happy Science University, Chosei-Chiba, Japan \\ ${ }^{2}$ University of Yamanashi, Kofu, Japan \\ ${ }^{3}$ Kyushu University, Fukuoka, Japan \\ Email: `hiroshi-okawa@happy-science.university, kir359458.15000192@kagoya.net, umwelt@mx3.nns.ne.jp, \\ kojima@triam.kyushu-u.ac.jp, akitsu@yamanashi.ac.jp
}

How to cite this paper: Okawa, H., Kuroda, H., Hirayama-Katayama, K., Kojima, S.-I. and Akitsu, T. (2019) Plasma-Electrolysis of Dinitrophenol in Gas-Liquid Boundary and Interpretation Using Molecular Orbital Theory. World Journal of Engineering and Technology, 7, 141-157.

https://doi.org/10.4236/wjet.2019.71010

Received: December 25, 2018

Accepted: January 28, 2019

Published: January 31, 2019

Copyright $\odot 2019$ by author(s) and Scientific Research Publishing Inc. This work is licensed under the Creative Commons Attribution International License (CC BY 4.0).

http://creativecommons.org/licenses/by/4.0/

\begin{abstract}
The advanced oxidation of 2,4-dinitrophenol (DNP), 2,5-DNP, and 3,4-DNP in aqueous solution has been investigated using a multi-gas, dielectric barrier discharge. Dielectric barrier discharge was operated in the aqueous solution and gas boundary. The degradation was measured by high performance liquid chromatography (HPLC). The acceleration of the advanced-oxidation has been investigated by the combination of the anion exchange polymer membrane. The result indicated that the degradation pathways involve a rapid detachment of the nitro group and a slow opening of the aromatic-ring. The hydroxyl radical and the excited hydroxyl anion are responsible for the primary attack of the DNP with the production of dihydroxy-nitrobenzenes. The attack of hydroxyl radical occurs at the benzene ring carbon activated by the presence of a phenolic $\mathrm{OH}$ group and a nitro group. The result suggested that the reaction is dominated by a pseudo-first order kinetic reaction. The degradation process is interpreted using Molecular Orbital Theory.
\end{abstract}

\section{Keywords}

Dielectric Barrier Discharge, Dinitrophenol, Advanced Oxidation, Molecular Orbital Theory

\section{Introduction}

A specific feature of the dielectric barrier discharge electrolysis is the excitation of oxygen molecules in the space surrounding the electrode and the chemical 
reaction at the interface between the plasma and the aqueous electrolyte. In the primary reaction gaseous region surrounding the electrode, water vapors are dissociated by the collision with excited atoms. In the water region, active species are generated by the dissociation of hydrogen peroxide:

$$
{ }^{*} \mathrm{OH}, \mathrm{OH}^{-},{ }^{*} \mathrm{H}, \mathrm{O}_{2}^{-}
$$

Nitrophenols (NP) are industrial products and have been detected in urban and agricultural waste. NPs are intermediates in agricultural chemistry, pesticide and dye synthesis such as artificial-indigo. The Yuzen-Nagashi (washing the Yuzen-printing in the river) was a traditional sight seen in the old KAMOGAWA River. It was not until late 1950s that this tradition was regally prohibited from the environmental point of view. Because of the high stability of the multi-ring aromatic compounds and low efficiency in the bio-degradation, the pollution of drinking-water reservoirs is attracting attentions in recent years. The purification of wastewaters is very difficult since some of multi-ring aromatic compounds are resistant to the bio-degradation and considered priority toxic pollutants, in concern due to the carcinogenic effect and endocrine disruptive effects. The advanced oxidation is attracting attentions as the cutting-edge technology for pollution of drinking-water reservoirs by aromatic compounds.

The decomposition of the aromatic compound is studied in several forms: the streamer discharge in liquid; the direct current contact glow discharge [1]-[11]; and high intensity UV radiation [12]. In a recent work, the decontamination of 2,6-dibromophenol (DBP) has been studied using a compact dielectric barrier discharge [13]. A comparative study using working gases: argon, nitrogen, oxygen, and air (20\% oxygen and $80 \%$ nitrogen mixture) revealed the utility of the degradation in the air-plasma. In this work, we compared the degradation of three types of dinitrophenols (DNP): 2,4-DNP; 2,5-DNP; and 3,4-DNP. The nitric anion was produced from the decomposition as well as the oxidation of nitrogen in the working gas. The interruption using anion exchange polymer made the degradation-process short. Chemical reactions with sulfate radical-based oxidation [14] and $\mathrm{Fe}^{2+}$ ion based reaction (Fenton reaction) [15] and ozone injection are attracting attentions as a method for the in-situ oxidation. Plasma-oxidation is based on the short life time active species, and it is worthwhile studying the dependence on the reactor structure.

Chemical reaction between the organic compound and the active component is discussed with Molecular Orbital Theory, considering the energy level of the Lowest Unoccupied Molecular Orbital (LUMO) and Highest Occupied Molecular Orbital (HOMO) and the Frontier-electron density theory.

\section{Material and Method}

\subsection{Apparatus and the Experimental Setting}

Figure 1 shows the dielectric barrier discharge plasma source. This plasma source consists of a quartz tube, $3.0 \mathrm{~mm}$ outer diameter and $1.4 \mathrm{~mm}$ inner diameter and an electrode, $\mathrm{W} / \mathrm{Re}(6 \%)$ wire, $0.6 \mathrm{~mm}$ in diameter located along the 


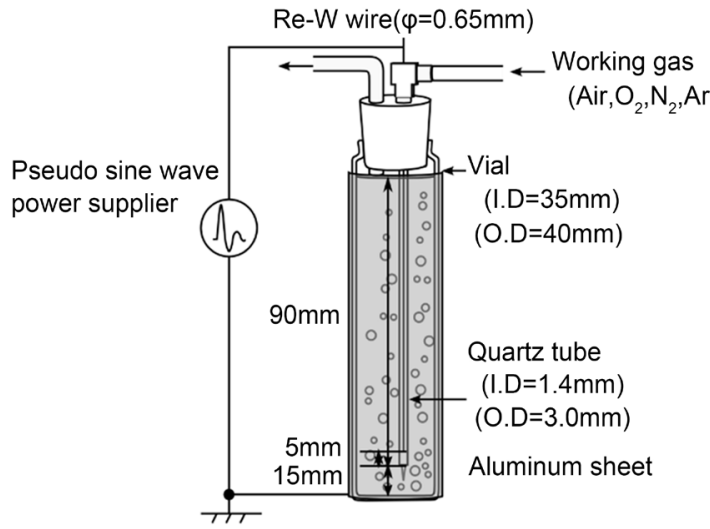

(a)

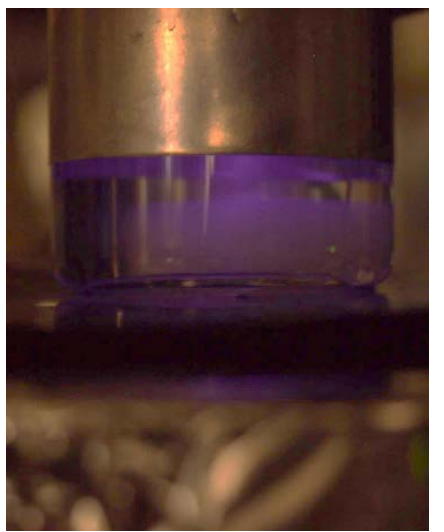

(b)

Figure 1. Dielectric barrier discharge plasma: (a) Structure of the plasma source consists of a quartz tube and an high voltage electrode, W/Re wire located at the center; (b) Dielectric barrier discharge in a liquid gas boundary, working gas: air [13].

center. These components are assembled with a Teflon Cajon-type elbow coupler. The quartz tube of the plasma source is immersed in the water-solution, which is connected to the ground electrode through the capacitive coupling. The power source is a quasi-sinusoidal wave inverter, $16.69-16.94 \mathrm{kHz}, 8.48-7.84 \mathrm{kV}$, peak to peak, (Type 10AC-24, Logy Electronics, Tokyo, Japan). The discharge voltage was measured with $\mathrm{P}-3000$ high voltage prove and the discharge current was measured with TCP312 current prove clamped to the ground side wire with preamplifier TCPA300 (Tektronix, Beaverton, USA) (Figure 2).

In the dielectric barrier discharge, myriads of spikes are observed in the current as shown in Figure 3. Discharge power was measured by integrating the area of the digitized Lissajous figure shown in Figure 4. The concentration of the remaining DNP was measured with liquid chromatograph, L-6000 (Hitachi Co., Japan) equipped with UV-detector, L-4200, (Hitachi Co., Japan) with column Waters X-bridge 4.6, $250 \mathrm{~mm}$. TOC measurement was carried out by TOC-LCSH/CSN and auto sampler, ASI-L, (Shimadzu Co., Japan) Ion chromatography for anion detection, ICS-1100 (Dionex), with column IonPac AS22 (Dionex,) and guard column, IonPac, AG22 (Dionex). In the ion chromatography, the detector was replaced to the electro-conductive detector. The overall reproducibility at higher density and the effect of the anion exchange was examined using liquid chromatograph, HPLC Prominence-I LC-2030Plus, (Shimadzu Co., Japan) installed with UV-detector and a reverse mode column: Xbridge C-18, $5 \mu \mathrm{m}$. $\mathrm{pH}$ was measured with HM-25R type pH meter (DKK-TOA Corporation, Tokyo, Japan).

\subsection{Measurement on the Basis of $Q$ versus V Lissajous Figure}

Figure 4 shows the $\mathrm{Q}$ versus $\mathrm{V}$ Lissajous figure and the measurement scheme. The total capacitance $\mathrm{C}_{\mathrm{PR}}$ includes the dielectric barrier discharge in the gas-region as well as the capacitance across the water region. Monitor capacitor is $4200 \mathrm{pF}$. For example, the one cycle along the contour, $10^{-7} \mathrm{C}$ along the vertical axis multiplied by $5 \times 10^{3} \mathrm{~V}$ along the horizontal axis is equivalent to $5 \times 10^{-4}$ 


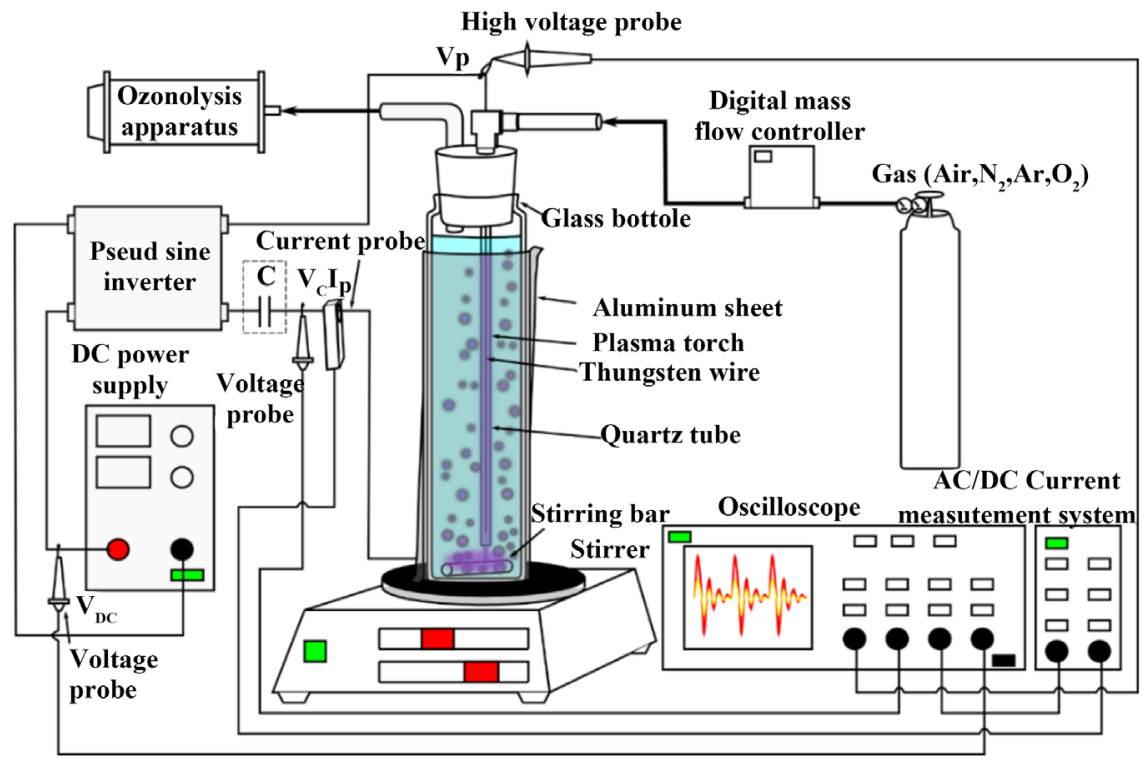

Figure 2. Experimental settings.

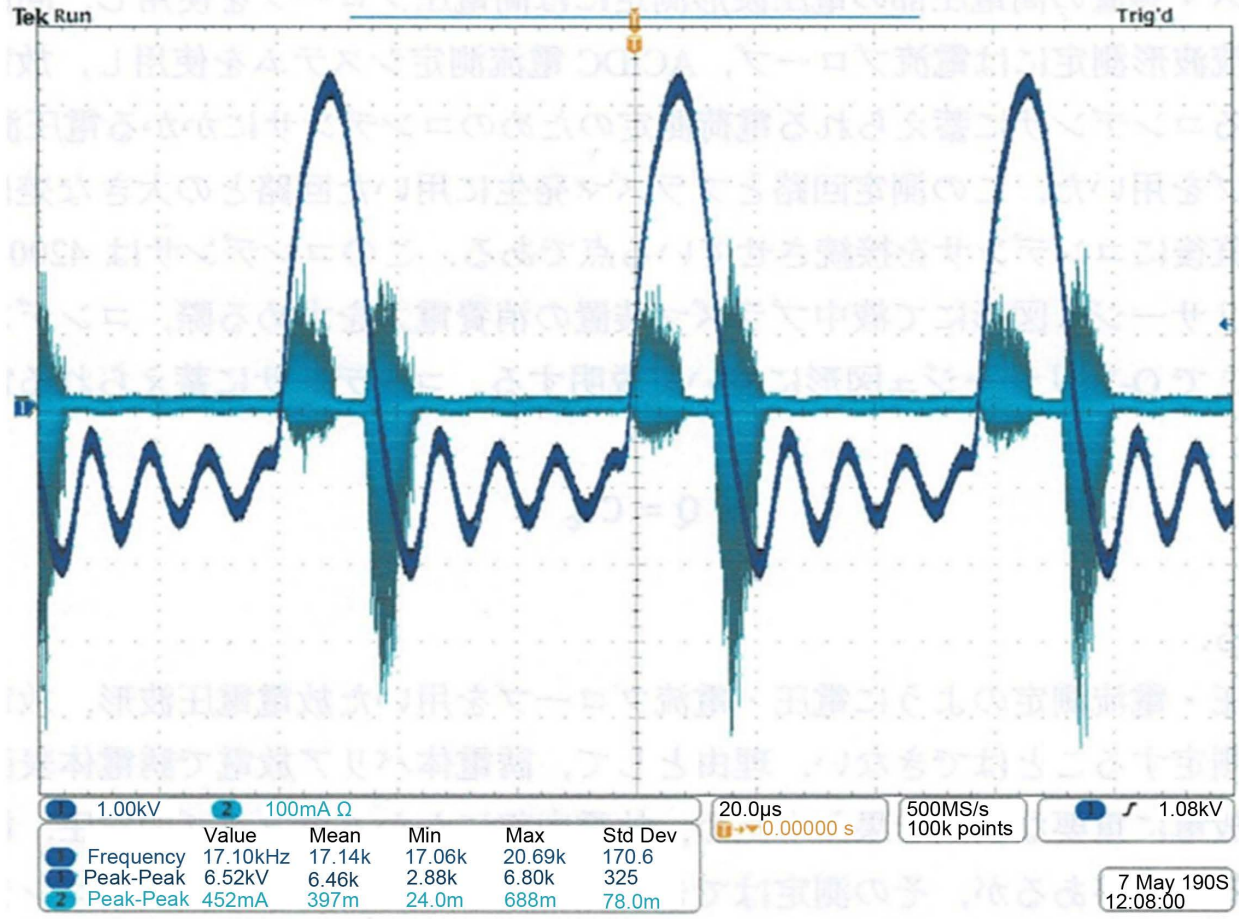

Figure 3. Voltage and current wave forms; Voltage waveform: $1 \mathrm{kV} /$ div. $6.5 \mathrm{kV}$ peak-to-peak; Current waveform: $100 \mathrm{~mA} /$ div. $452 \mathrm{~mA}$ peak-to-peak. Control voltage: $11.0 \mathrm{~V}$.

$\mathrm{J} /$ cycle. The electrical power input at $16.5 \mathrm{kHz}$ is $8.25 \mathrm{~W}$. Table 1 shows the dependence of the output voltage on the control voltage (DC input) and the discharge power. When the plasma source was operated at the control voltage of 13 volts and higher, the discharge formed thermal glow discharge. This discharge mode is not efficient for the advanced oxidation. The plasma electrolysis is operated at relatively low power consumptions $<12 \mathrm{~W}$. 


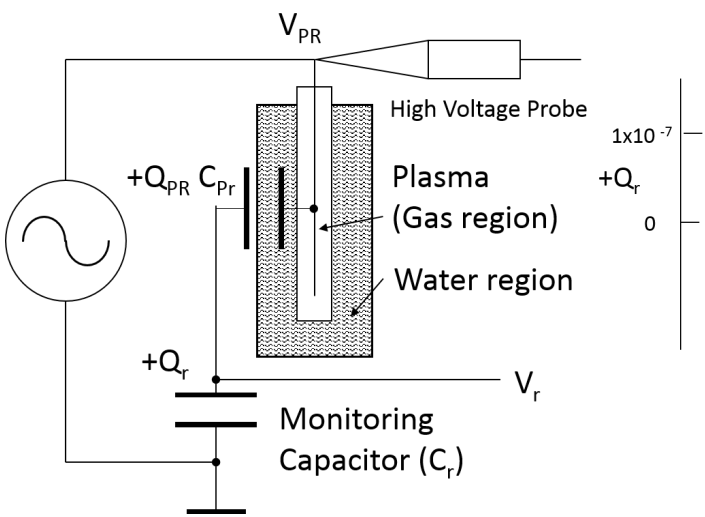

(a)

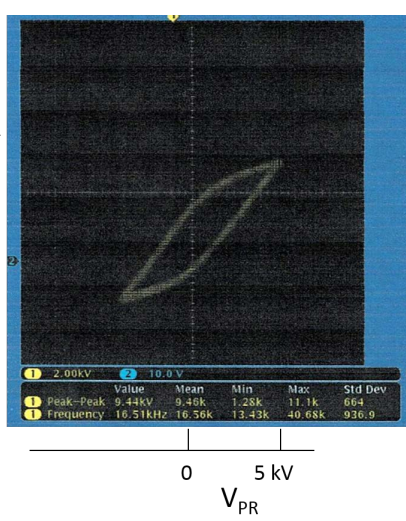

(b)

Figure 4. Q versus V Lissajous; (a) Scheme; (b) Typical contour, Control voltage: 11.0 V.

Table 1. Estimation of the discharge power and operational parameter.

\begin{tabular}{lccc}
\hline \multirow{2}{*}{ Discharge Mode } & \multicolumn{2}{c}{ Experimental parameters } & \\
\cline { 2 - 3 } & Control voltage $(\mathrm{V})$ & Frequency $(\mathrm{kHz})$ & Power $(\mathrm{W})$ \\
\hline Dielectric Barrier & 6.45 & & 3.69 \\
$\quad$ Discharge & 8.66 & $16.34-94$ & 6.96 \\
& 9.46 & & 9.48 \\
Glow Discharge & $11.0 \mathrm{a}$ & & 12.36 \\
\hline
\end{tabular}

a: Operational parameter.

\subsection{Anion-Exchange Polymer}

Next figure shows a typical example of gel type poly-styrene base alkalized trimethyl-ammonium polymer (Sanei Chemical, Kumamoto, Japan) $\mathrm{NO}_{3}^{-}$anion was exchanged with $\mathrm{OH}^{-}$anion (Figure 5).

\section{Experimental Result}

The efficiency of the plasma degradation is compared for dinitrophenols: 2,4-DNP, 2,5-DNP, and 3,4-DNP.

\subsection{Plasma-Degradation of Dinitrophenol Solution}

Figure 6 shows the experimental comparison of the degradation: the concentration and total organic carbon (TOC). The amount of carbon consists of TOC and Inorganic Carbon (IC). In this work, TOC is detected as the amount of $\mathrm{CO}_{2}$ from the solid body of the solution dried and incinerated in a furnace (650 to 1200 degree $\mathrm{C}$ ). The detachment of $\mathrm{NO}_{2}$ is completed in 10 minutes. Longer process is needed for the reduction of TOC, which remains almost 70 percent of the initial concentration. This result indicates the production of the intermediate product, such as hydroquinone.

Next, Figure 7 shows the evolution of the concentration of $\mathrm{NO}_{3}^{-}$and $\mathrm{pH}$. 


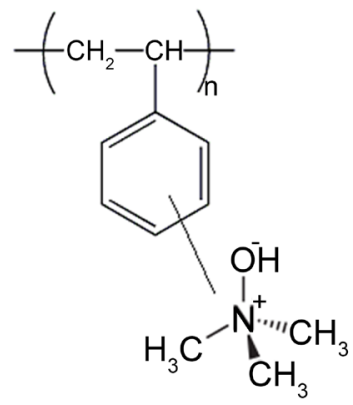

Figure 5. 2-D Molecular structure of the anion exchange polymer.

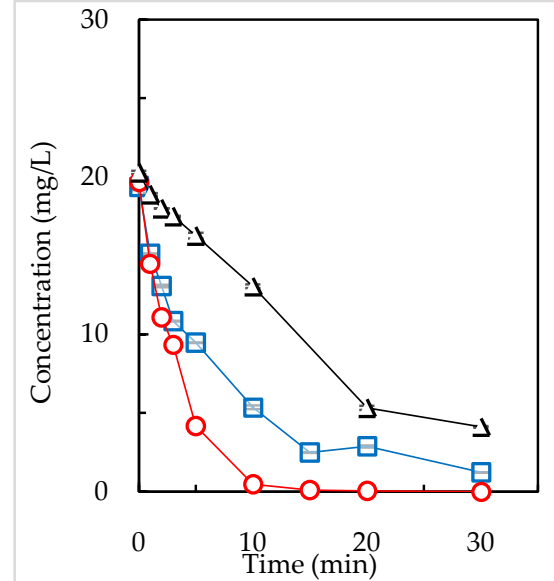

(a)

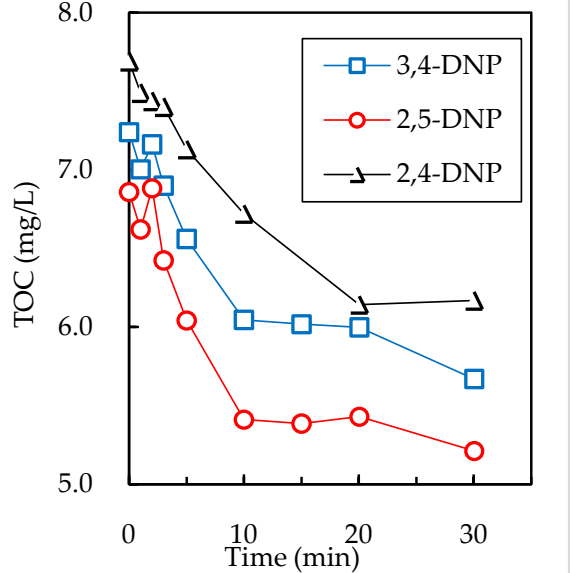

(b)

Figure 6. Liquid chromatography measurement and TOC: (a) Concentration of dinitrophenyls; 3,4-DNP; 2,5-DNP; 2,4-DNP. Eluent:methanol:ultra-pure water = 7:3. (b) Total Organic carbon.

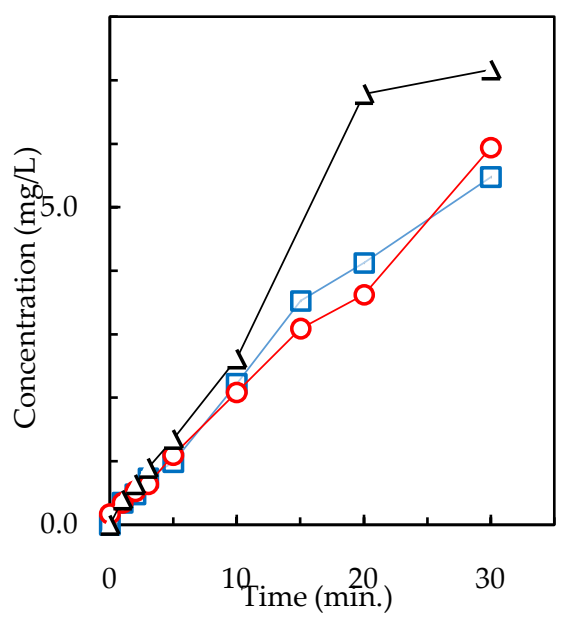

(a)

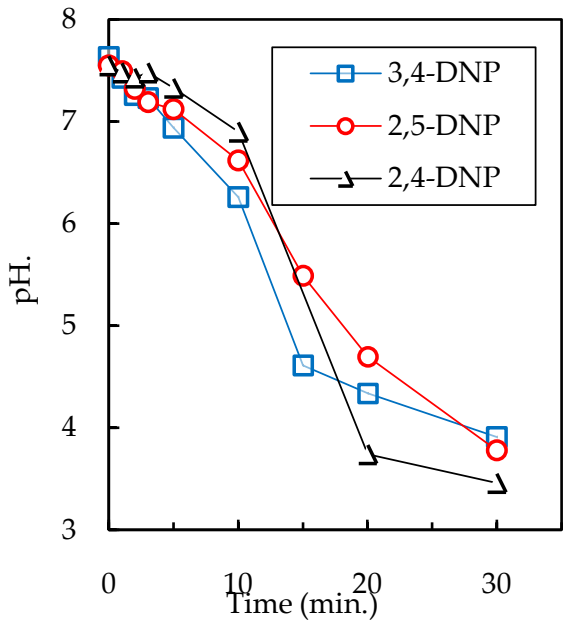

(b)

Figure 7. Ion chromatography and $\mathrm{pH}$ measurement; (a) Concentration of $\mathrm{NO}_{3}^{-}$; (b) $\mathrm{pH}$.

Table 2 shows the concentration and $\mathrm{pH}$ after 60 minutes. Table 2 summarizes the TOC, concentration of DNP and $\mathrm{NO}_{3}^{-}$after 60 minutes. 
Table 2. Concentration, TOC and $\mathrm{pH}$.

\begin{tabular}{|c|c|c|c|c|c|}
\hline \multirow[b]{2}{*}{ DNP Specie } & \multicolumn{5}{|c|}{ Experimental result } \\
\hline & $\begin{array}{c}\text { TOC } \\
(\mathrm{mg} / \mathrm{L})\end{array}$ & $\begin{array}{c}\text { DNP Concentration } \\
(\mathrm{mg} / \mathrm{L})\end{array}$ & $\mathrm{NO}_{3}^{-}$ & $\begin{array}{l}\text { Concentration } \\
(\mathrm{mg} / \mathrm{L})\end{array}$ & $\mathrm{pH}$ \\
\hline 2,5-DNP & $4.310^{\mathrm{a}}$ & 0 & & 20.6 & 3.5 \\
\hline 3,4-DNP & 5.139 & 0 & & 19.0 & 3 \\
\hline 2,4-DNP & 5.117 & 0.002 & & 19.6 & 2.99 \\
\hline
\end{tabular}

Apparently, the final concentration of $\mathrm{NO}_{3}^{-}$exceeds the original concentration of the nitro-group, and the solution shows acidity.

The weight of nitric anion is calculated, if two nitrogen atoms are converted to $\mathrm{NO}_{3}^{-}$, one oxygen comes from the working gas. From the moll ratio, 124/184.106 times $[20 \mathrm{mg} / \mathrm{L}]=13.47 \mathrm{mg} / \mathrm{L}$. The increase in $\mathrm{NO}_{3}^{-}$anion should be attributed to the oxidation in the working gas. This acid solution is not suitable for the release. It would be necessary to improve $\mathrm{pH}$ to be neutral, by neutralization using proper reagent after the anion exchange.

\subsection{Degradation in the Initial Phase}

Figure 8 shows the evolution of the concentration in semi-logarithmic scale.

The concentration can be expressed as exponential recurrence function as in the following form and plotted along symbols. R squared ranges from 0.9661 to 0.9859. Increase in the discharge current causes the change of the discharge mode to the transfer glow discharge (Table 3).

$$
\ln \left(\frac{C_{t}}{C_{0}}\right)=-a t-b, C_{0}=20[\mathrm{mg} / \mathrm{L}]
$$

\subsection{Anion Exchange and Color Reaction}

The plasma process increases neutral materials in the object, even if our aim is the ionized or excited radicals. The anion exchange polymer captured the excessive material, $\mathrm{NO}_{3}^{-}$and exchanged with hydroxyl anion $\mathrm{OH}^{-}$. Figure 9 shows the concentration of 2,4-DNP and the typical color of the solution.

The anion-exchange accelerated the plasma-degradation, and the final concentration was $2.9 \mathrm{ppm}$ in the total processing time of 20 minutes. The characteristic yellow color of 2,4-DNP was used as an indicator. 2,4-DNP in liquid shows the absorption spectrum in the visible-UV wave length, as shown by the dark line in Figure 10. Figure 10 and Figure 11 show the model calculation of the absorption spectrum, and corresponding the LUMO and HOMO surface of $2,4-\mathrm{DNP}$ in an aqueous model. The hydrogen atom in $\mathrm{OH}$ is oxidized and removed, and the bond between $\mathrm{C}$ and $\mathrm{O}$ is now double bond (Keto-type). The bond between $\mathrm{N}$ and $\mathrm{C}$ in the para-position is double bond (Enol-type). The double bonds in the benzene ring are now localized. The visible-UV absorption of this system shows a broad peak of blue light (dark line), and the medium shows the complementary color, yellow. 


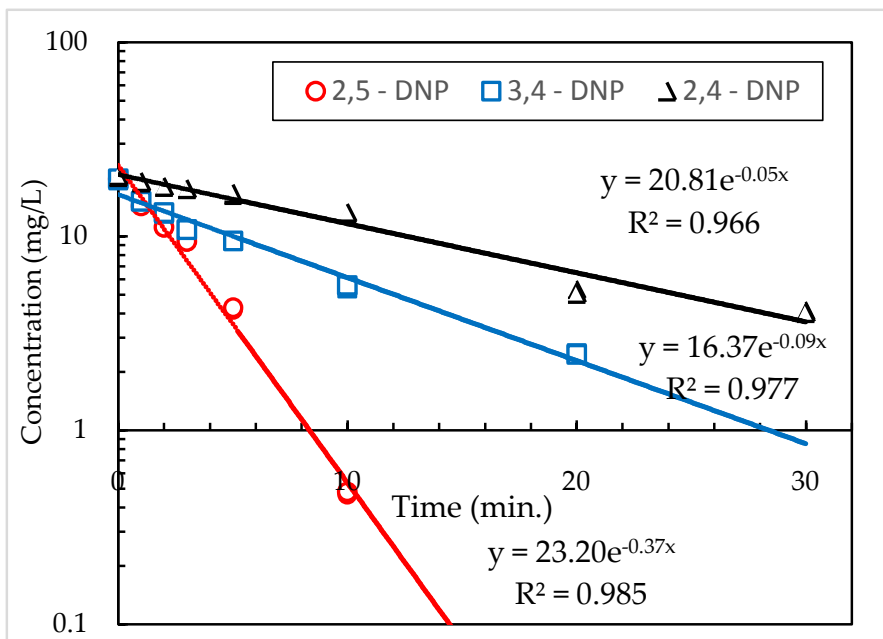

Figure 8. Evolution of the concentration in the initial stage.

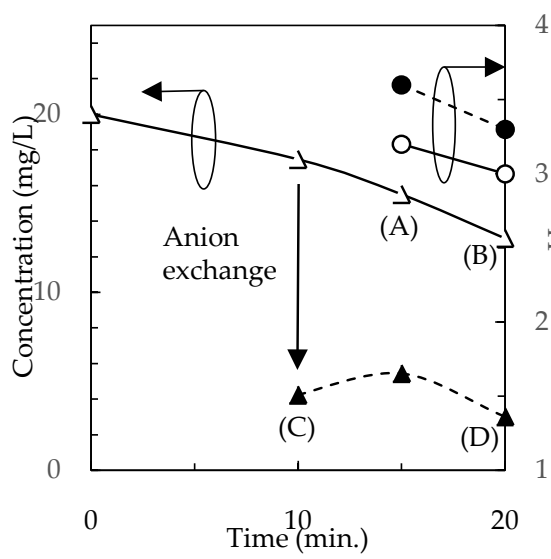

(a)

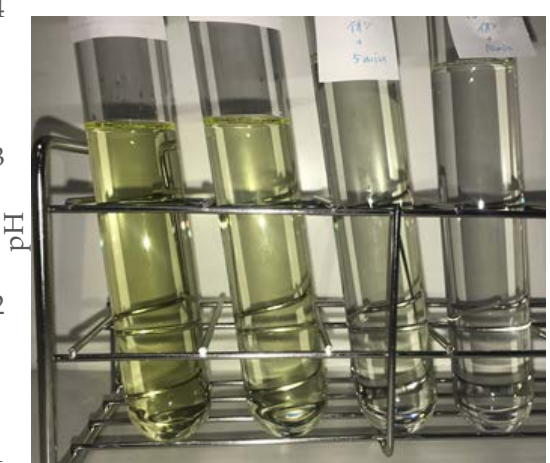

$\begin{array}{llll}(\mathrm{A}) & (\mathrm{B}) & \text { (C) } & \text { (D) }\end{array}$

(b)

Figure 9. Shortcut of degradation by the anion exchange: (a) concentration of 2,4-DNP; and $\mathrm{pH}$. Filled symbols indicates the result of the anion exchange; (b) (A) to (B): Plasma degradation (15, $20 \mathrm{~min}$.), (C) after the anion exchange, (D) plasma degradation (10 min.) after the anion exchange.

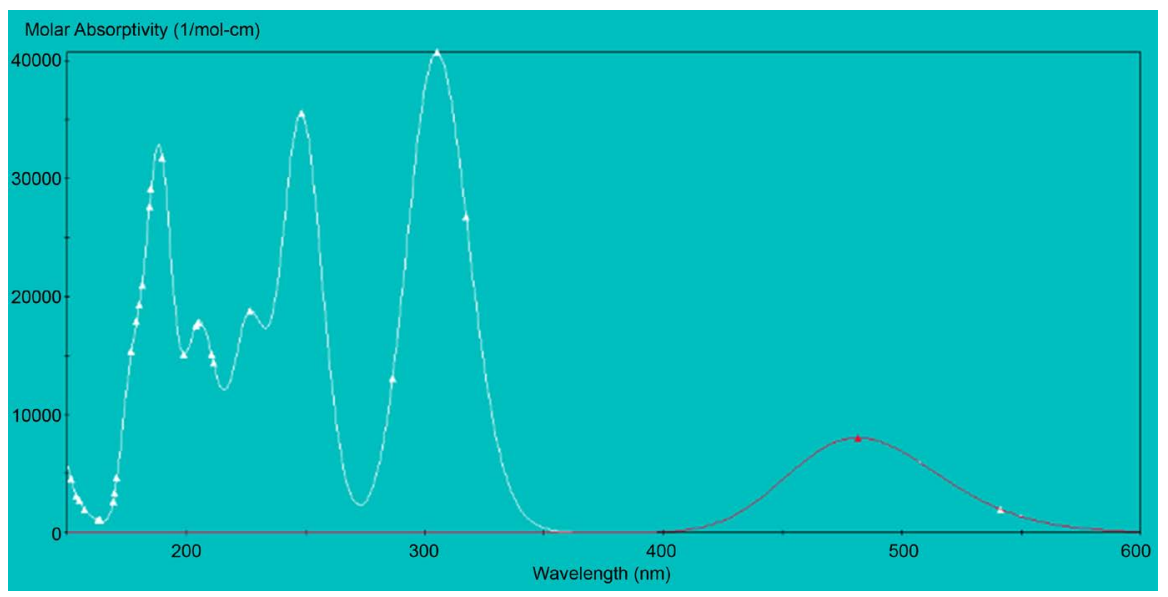

Figure 10. Absorption spectrum in UV and visible wave length. 
Table 3. Normalized reaction coefficient.

\begin{tabular}{cccc}
\hline \multirow{2}{*}{ Sample } & \multicolumn{3}{c}{ Recurrent Function } \\
\cline { 2 - 4 } & $\mathrm{a}$ & $\mathrm{b}$ & R-squared \\
\hline 2,4-DNP & 0.058 & 0.04 & 0.9661 \\
3,4-DNP & 0.099 & -0.200 & 0.9776 \\
2,5-DNP & 0.377 & 0.148 & 0.9859 \\
\hline
\end{tabular}

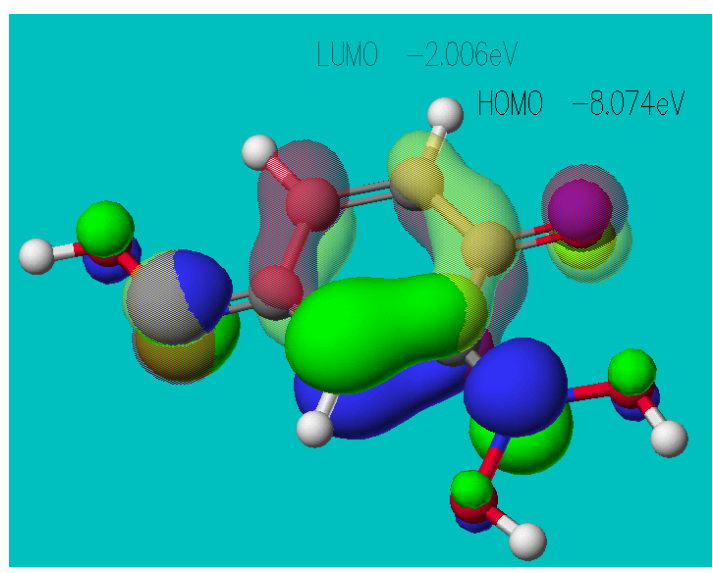

Figure 11. Model calculation of the LUMO/HOMO for 2,4-DNP in aqueous model.

\section{Discussion}

\subsection{Interpretation by Frontier Electron Density Calculation}

Lukes et al. reported the enhancement of ${ }^{*} \mathrm{OH}$ radical production and $\mathrm{O}_{3}$ decomposition in the presence of $\mathrm{N}_{2}$ molecules in humid air, through the following reactions [11].

Dissociation and ionization

$$
\begin{aligned}
& \mathrm{H}_{2} \mathrm{O}+\mathrm{e} \rightarrow \mathrm{OH}^{-}+\mathrm{H}^{+}+e \\
& \mathrm{H}_{2} \mathrm{O}+\mathrm{e} \rightarrow{ }^{*} \mathrm{OH}+{ }^{*} \mathrm{H}+e
\end{aligned}
$$

Reactions including excited oxygens

$$
\begin{gathered}
\mathrm{O}\left({ }^{1} \mathrm{D}\right)+\mathrm{H}_{2} \mathrm{O} \rightarrow 2 \mathrm{OH}^{*} \\
\mathrm{O}\left({ }^{1} \mathrm{D}\right)+\mathrm{O}_{2} \rightarrow \mathrm{O}_{3}
\end{gathered}
$$

Reactions including $\mathrm{N}_{2}$ molecules:

$$
\begin{gathered}
\mathrm{N}_{2}+\mathrm{e} \rightarrow 2 \mathrm{~N}^{*}+\mathrm{e} \\
\mathrm{O}\left({ }^{1} \mathrm{D}\right)+\mathrm{NO} \rightarrow \mathrm{NO}_{2} \\
\mathrm{~N}^{*}+\mathrm{O}_{3} \rightarrow \mathrm{NO}+\mathrm{O}_{2} \\
\mathrm{NO}+\mathrm{O}_{3} \rightarrow \mathrm{NO}_{2}+\mathrm{O}_{2}
\end{gathered}
$$

Reactions including the metastable state of $\mathrm{N}_{2}$ molecules:

$$
\mathrm{N}_{2}\left(\mathrm{~A}^{3} \Sigma\right)+\mathrm{H}_{2} \mathrm{O} \rightarrow \mathrm{N}_{2}+{ }^{*} \mathrm{OH}+{ }^{*} \mathrm{H}
$$


Inhibition of $\mathrm{O}_{3}$ production and enhancement of $\mathrm{OH}^{*}$ formation:

$$
\begin{aligned}
\mathrm{OH}^{-}+\mathrm{O}_{3} & \rightarrow{ }^{*} \mathrm{O}_{2}^{-}+\mathrm{HO}_{2}^{*} \\
\mathrm{O}_{3}+3 \mathrm{HO}_{2}^{*} & \rightarrow 3 \mathrm{OH}^{*}+3 \mathrm{O}_{2}
\end{aligned}
$$

Production of superoxide: Oxygen molecule is the primary acceptor of electrons and forms ${ }^{*} \mathrm{O}_{2}^{-}$

$$
\mathrm{O}_{2}+\mathrm{e} \rightarrow{ }^{*} \mathrm{O}_{2}^{-}
$$

Production of hydroxyl radicals: super oxide is highly reactive super anions and form hydrogen peroxide in the following chain reaction. Hydroxyl radical and hydroxyl anion are produced in the dissociation of hydrogen peroxide by the electron collision in the discharge area as well as by the decomposition of ozone in water reactions.

$$
\begin{gathered}
{ }^{*} \mathrm{O}_{2}^{-}+\mathrm{H}_{2} \mathrm{O} \rightarrow \mathrm{OH}^{-}+{ }^{*} \mathrm{HO}_{2} \\
{ }^{*} \mathrm{HO}_{2}+{ }^{*} \mathrm{HO}_{2} \rightarrow \mathrm{H}_{2} \mathrm{O}_{2}+\mathrm{O}_{2} \\
\mathrm{H}_{2} \mathrm{O}_{2}+{ }^{*} \mathrm{O}_{2}^{-} \rightarrow{ }^{*} \mathrm{OH}+\mathrm{OH}^{-}+\mathrm{O}_{2} \\
\mathrm{H}_{2} \mathrm{O}_{2}+\mathrm{e} \rightarrow{ }^{*} \mathrm{OH}+\mathrm{OH}^{-} \\
\mathrm{DNP}+\left\{{ }^{*} \mathrm{OH}+\mathrm{OH}^{-}\right\} \rightarrow \text { Produced system }
\end{gathered}
$$

Reactions related to $\mathrm{NO}_{2}^{-}$and nitrous acid, related to the production of nitrite ions and $\mathrm{ONOO}$, peroxonitrite:

$$
\begin{gathered}
\mathrm{NO}_{2}^{-}+\mathrm{H}_{2} \mathrm{O}_{2} \rightarrow \mathrm{ONO}_{2}^{-} \\
\mathrm{HNO}_{2}+\mathrm{H}_{2} \mathrm{O}_{2} \rightarrow \mathrm{HOONO}+\mathrm{H}_{2} \mathrm{O}
\end{gathered}
$$

One of merits of the present multi-gas dielectric barrier discharge is the comparison of the discharge characteristics in air and pure oxygen. Various reactive species are generated in the discharge region and the inhibition of the production of ozone. In the experiment, DNP with the different position of nitro group is examined using 2,4-DNP, 2,5-DNP and 3,4-DNP (Appendix). Using the molecular orbital theory, LUMO and HOMO energy of the starting system and the produced system were calculated considering hydroxyl radical and excited hydroxyl anion as active agents.

Figure 12 shows the frontier electron density for the radical reaction and the electrophilic reaction of 2,5-DNP, and Figure 13 shows the frontier electron density of 2,4-DNP.

In Figure 12, radical reaction frontier electron density is localized around carbon atoms of benzene ring (Figure 12(a)). The electrophilic reaction frontier electron density is localized in the ortho and para position with respect to $\mathrm{OH}$ group. Nitro group in this position is the target of the electrophilic replacement by $\mathrm{OH}$ radical (Figure 12(b)). Figure 12(c) shows the frontier electron density of the nucleophilic reaction.

In Figure 13, the radical reaction frontier electron density is localized around carbon atoms of benzene ring (Figure 13(a)). The electrophilic reaction frontier 


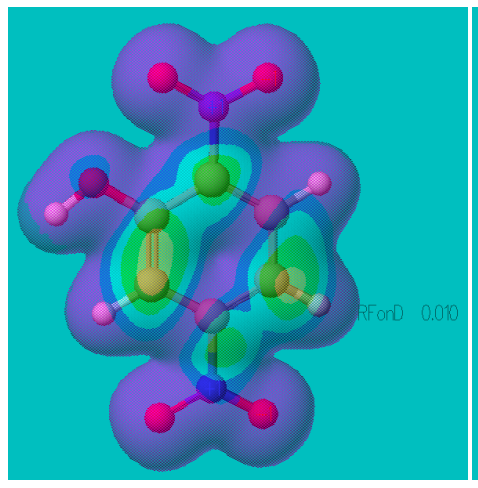

(a)

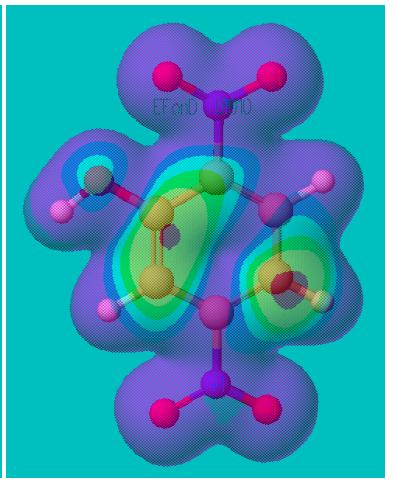

(b)

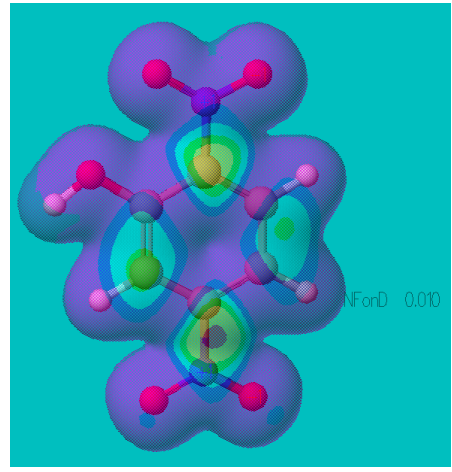

(c)

Figure 12. Frontier electron density; (a) Radical reaction; (b) Electrophilic reaction; (c) Nucleophilic reaction. Red: oxygen; Blue: nitrogen; Grey: carbon.

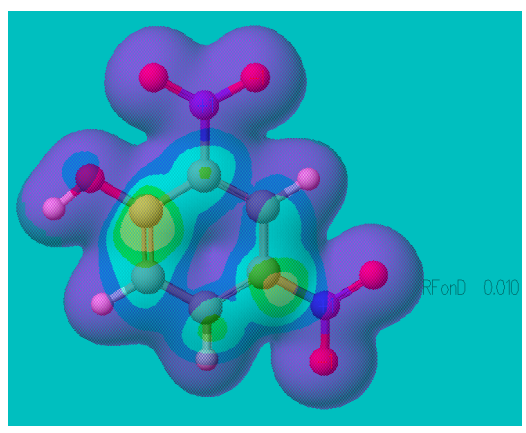

(a)

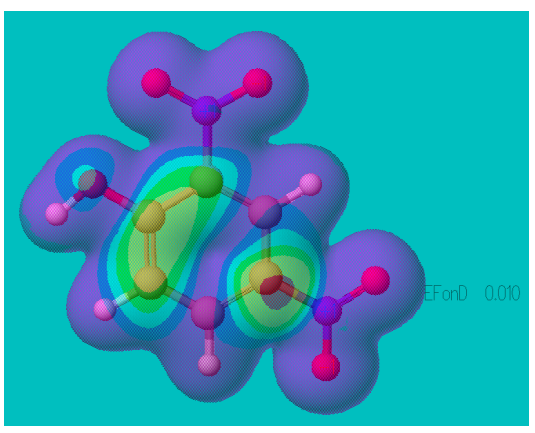

(b)

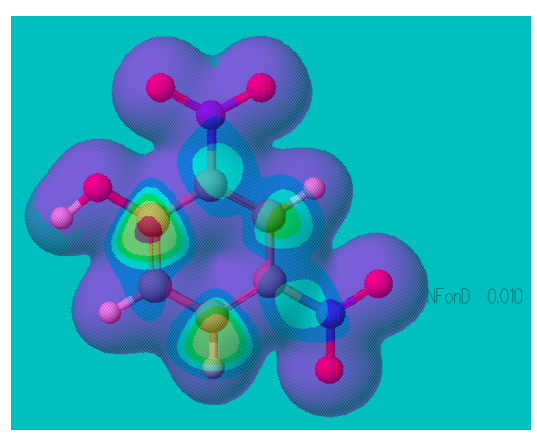

(c)

Figure 13. Frontier electron density; (a) Radical reaction; (b) Electrophilic reaction; and (c) Nucleophilic reaction for 2,4-DNP. Red: oxygen, Blue: nitrogen; Grey: carbon. 
electron density is localized in the ortho and para position with respect to $\mathrm{OH}$ group. Nitro group in this position is the target of the electrophilic replacement by $\mathrm{OH}$ radical (Figure 13(b)). Figure 13(c) shows the frontier electron density of the nucleophilic reaction. The area around the carbon atoms connected to nitro group shows high frontier electron density. Nitro group in this position is the target of the nucleophilic replacement reaction by excited $\mathrm{OH}$ anion. This reaction contributes the detachment of nitro group and the opening of the benzene ring. The area around the carbon atoms connected to nitro group shows high frontier electron density. Nitro group in this position is the target of the nucleophilic replacement reaction by excited $\mathrm{OH}$ anion. This reaction contributes the detachment of nitro group and the opening of the benzene ring.

\subsection{Interpretation by LUMO and HOMO Energy Calculation}

The effects of the frontier electrons in the Highest Occupied Molecular Orbital (HOMO) of the active component, $\mathrm{OH}^{-}$anion and $\mathrm{OH}^{*}$ radical and the Lowest Unoccupied Molecular Orbital (LUMO) of the target compound determines the reaction mechanisms [16] [17] [18]. Figure 14 shows the frontier electron density of the LUMO and HOMO, of the starting system 2,4-DNP, and Figure 15 shows the produced system, 1,2-OH-4-nitrobenzene.

In Figure 14, LUMO energy of the starting system is $-1.268 \mathrm{eV}$, and HOMO energy $-10.210 \mathrm{eV}$. As the excited $\mathrm{OH}^{-}$, anion shows LUMO energy $4.045 .89 \mathrm{eV}$ and higher HOMO energy $-10.375 \mathrm{eV}$. This reaction is directed to the nucleophilic reaction. $\mathrm{OH}^{*}$ radical shows singly occupied molecular orbit (SOMO) energy, $3.121 \mathrm{eV}$. This reaction is directed to electrophilic reaction directed to the HOMO level, -10.210. In Figure 15, LUMO energy is $-0.346 \mathrm{eV}$ and HOMO energy $-4.907 \mathrm{eV}$. For the reverse reaction, excitation energy is necessary for $\mathrm{NO}_{3}^{-}$(in $\mathrm{HNO}_{3}$ ).

Figure 16 shows the frontier electron density of the starting system, 2,5-DNP, where LUMO energyis $-2.634 \mathrm{eV}$ and HOMO energy $-10.068 \mathrm{eV}$, and Figure 17 shows the produced system, 1,2-OH-5-nitrobenzene, where LUMO energy is $-2.102 \mathrm{eV}$ and HOMO energy $-9.47 \mathrm{eV}$.

Figure 18 compares the LUMO and HOMO energy of 2,4-DNP with active

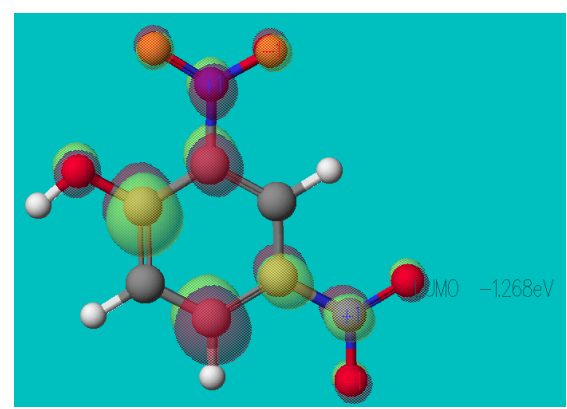

(a)

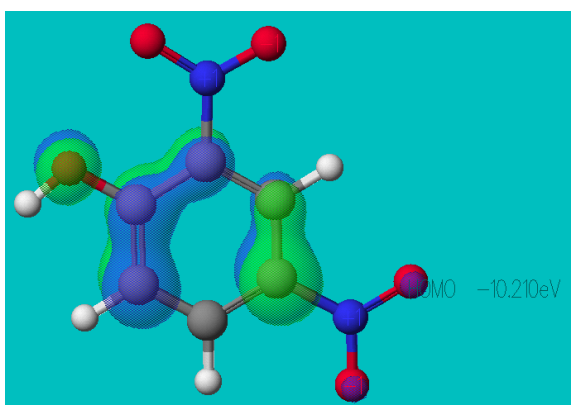

(b)

Figure 14. Frontier electron density of 2,4-DNP; (a) LUMO surface; (b) HOMO surface. Red: oxygen; Blue: nitrogen; Grey: carbon. 


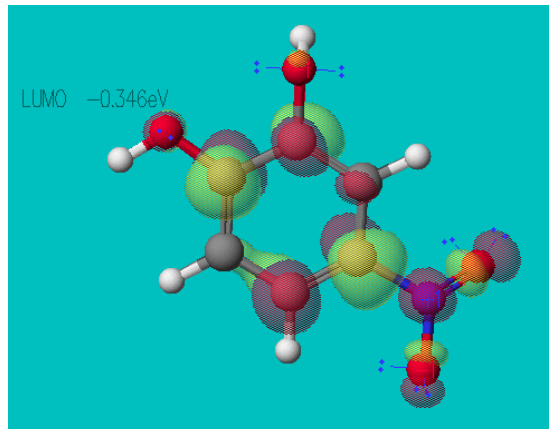

(a)

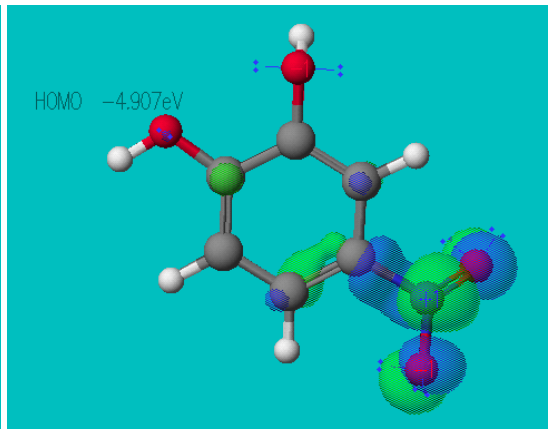

(b)

Figure 15. LUMO and HOMO surface of the produced system; (c) 1,2-OH-4-nitrobenzene, LUMO surface; (d) HOMO surface. Red: oxygen; Blue: nitrogen; Grey: carbon.

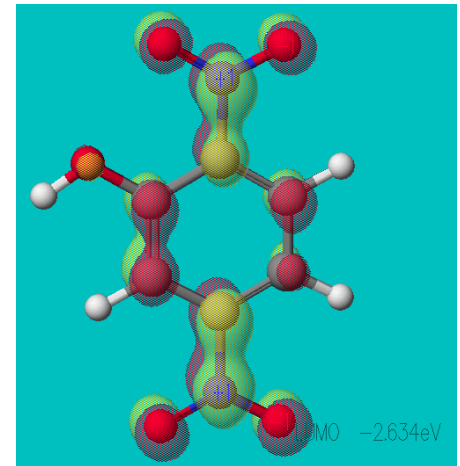

(a)

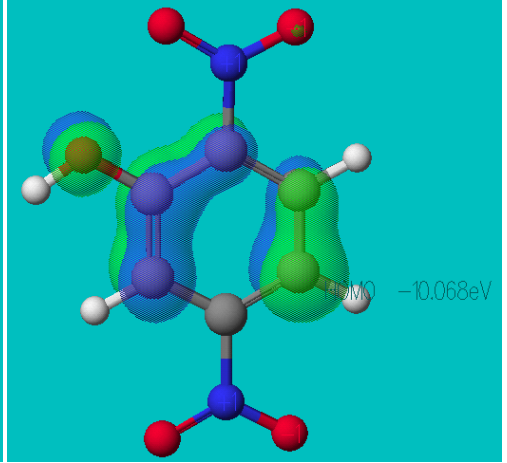

(b)

Figure 16. Frontier electron density of 2,5-DNP; (a) LUMO surface; (b) HOMO surface. Red: oxygen; Blue: nitrogen; Grey: carbon.

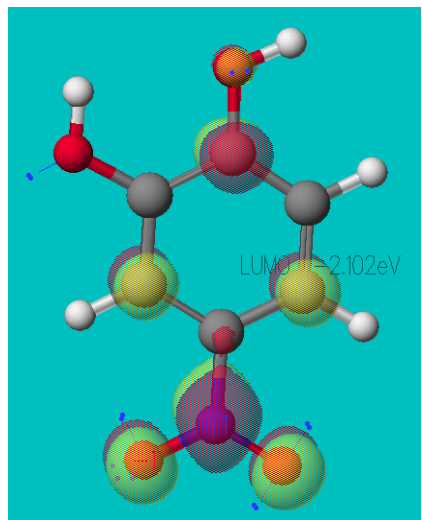

(a)

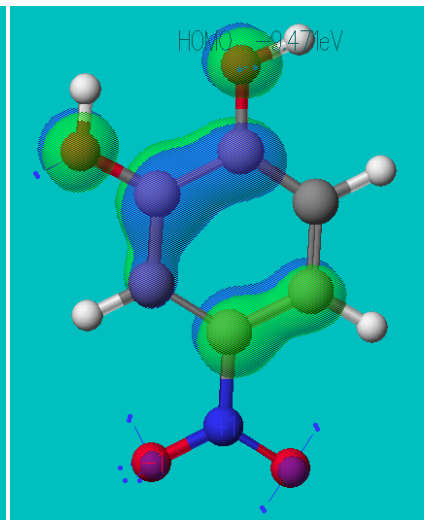

(b)

Figure 17. LUMO and HOMO surface of the produced system, 1,2-OH-5-nitrobenzene; (a) LUMO surface; (b) HOMO surface. Red: oxygen; Blue: nitrogen; Grey: carbon.

species. The LUMO energy of 2,4-DNP is $-1.268 \mathrm{eV}$ and excited energy of hydroxyl anion $\mathrm{OH}^{-}$is $4.045 \mathrm{eV}$. Excited hydroxyl anion is directed to nucleophilic reaction, which depends on the energy difference between the excited $\mathrm{OH}$ anion and 2,4-DNP, $5.313 \mathrm{eV}$. $\mathrm{OH}^{*}$ radical is characterized with the singly occupied molecular orbital (SOMO) at $3.121 \mathrm{eV}$. This electrophilic exchange reaction de- 
pends on the difference between the HOMO level of 2,4-DNP, $13.337 \mathrm{eV}$.

Figure 19 shows a comparison of $\mathrm{OH}$ anion (in $\mathrm{NaOH}$ ) with 2,4-DNP. This $\mathrm{OH}^{-}$anion shows HOMO level lower than the LUMO level of 2,4-DNP. The difference between the LUMO level of 2,4-DNP and the HOMO level of OH anion (in $\mathrm{NaOH}$ ) is necessary excitation energy, $1.342 \mathrm{eV}$. Although the exchange reaction is exothermic reaction in total, this exchange reaction is not observed in the experiment. Similarly for the reverse reaction in Figure 19(b), the excitation energy of $12.314 \mathrm{eV}$ is necessary.

The exchange reactions are limited by the supply of excited hydroxyl radical and excited hydroxyl anion, $\mathrm{OH}^{-}$and $\mathrm{OH}^{\star}$. The reverse reaction limited by the energy difference. Figure 20 shows the LUMO and HOMO energy level of the starting system, 2,5-DNP $+\mathrm{OH}^{-}$and the produced system. 1,2-OH-5-nitrobenzene $+\mathrm{NO}_{3}^{-}\left(\mathrm{HNO}_{3}\right)$. LUMO energy is $-2.668 \mathrm{eV}$ and excited energy of hydroxyl anion $\mathrm{OH}^{-}$is $4.045 \mathrm{eV}$. In moderately acidic conditions, ONOO, peroxonitrite is formed in the water region. The HOMO energy is $-10.241 \mathrm{eV}$ and $-10.246 \mathrm{eV}$, the LUMO energy is $-1.535 \mathrm{eV}$. This cluster attracts electrons and attacks the electrophilic reaction region.

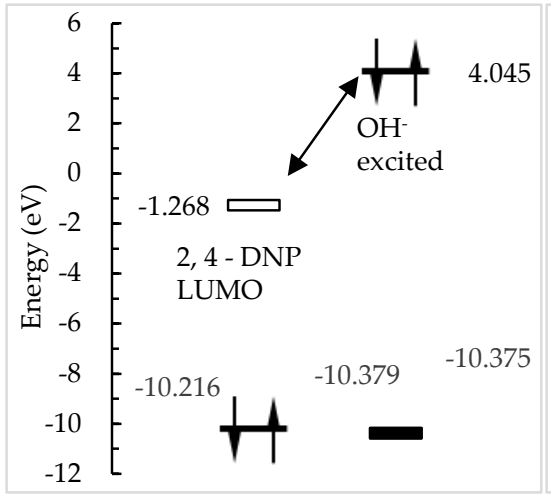

(a)

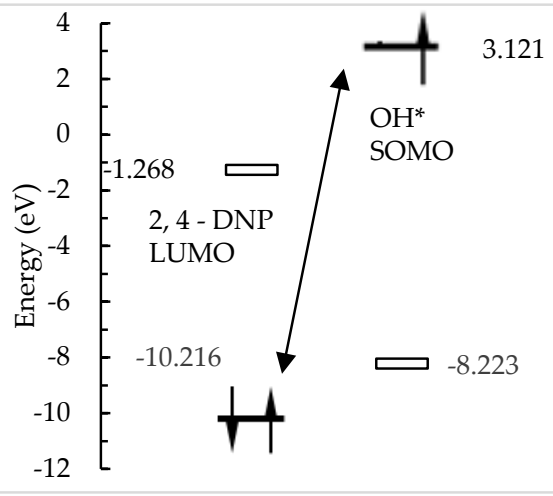

(b)

Figure 18. LUMO and HOMO energy profile; (a) Starting system, 2,4-DNP $+\mathrm{OH}^{-}$; (b) Starting system, 2,4-DNP $+\mathrm{OH}^{\star}$.

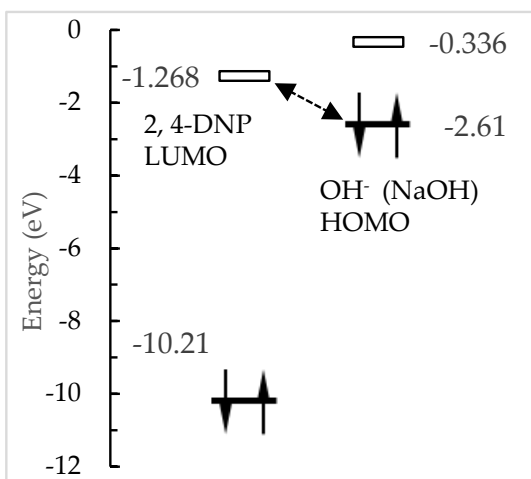

(a)

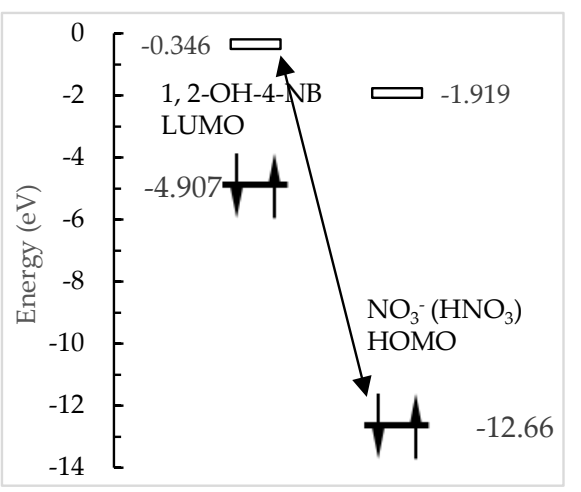

(b)

Figure 19. LUMO and HOMO energy profile; (a) Starting system, 2,4-DNP $+\mathrm{OH}^{-}$; (in $\mathrm{NaOH}$ ); (b) Produced system, 1,2-OH-4-Nitrobenzene $+\mathrm{NO}_{3}^{-}$(in $\mathrm{HNO}_{3}$ ). 


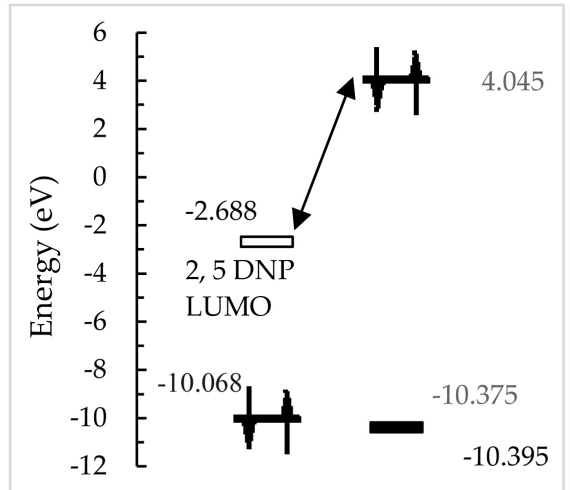

(a)

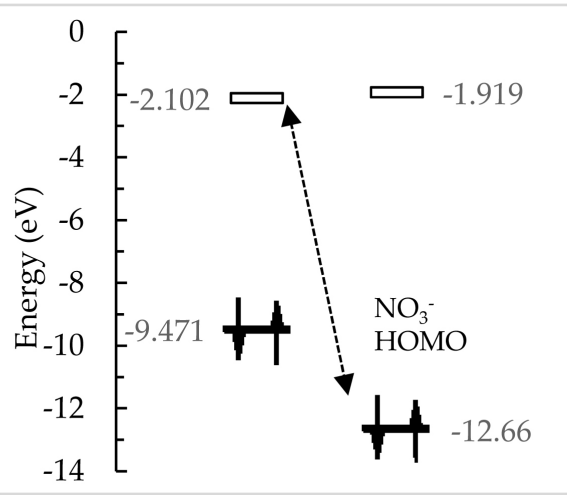

(b)

Figure 20. Energy profile; (a) Starting system, of 2,5-DNP $+\mathrm{OH}^{-}$; (b) Produced system. 1,2-OH-5-nitrobenzene $+\mathrm{NO}_{3}^{-}\left(\mathrm{HNO}_{3}\right)$.

In this work, the frontier electron density and HOMO and LUMO energy level are calculated by Biomedical CAChe (Fujitsu, Japan) [18] and SCIGRESS (Fujitsu, Japan) [19].

\section{Conclusion}

Plasma-degradation of the dinitrophenyl was studied using a compact dielectric barrier discharge in a quartz tube, immersed into the liquid surface. As the dielectric barrier discharge can be operated at low electric power, this method is a feasible solution for the water remediation. In the air-plasma treatment, the accumulation of nitric anion was a problem. A simple solution, the anion exchange was found. This process can interrupt the long degradation process to short solution. The exchange of the nitro system of the DNPs was interpreted by the Molecular Orbital Theory. The LUMO level of the organic compound is lower than the HOMO level of the active component $\mathrm{OH}^{-}$or SOMO level of $\mathrm{OH}^{*}$. The reaction proceeds to the detachment of nitric anion. In the future activities, the adaptive combination of the present method with other difficult materials and the improvement of the efficiency will be the necessary development step.

\section{Acknowledgements}

This research received a fund from Future Science Institute, Tokyo, Japan. The authors express their gratitude to Mr. Kento Nakai and Mr. Kenya Yabu.

\section{Conflicts of Interest}

The authors declare no conflicts of interest regarding the publication of this paper.

\section{References}

[1] Locke, B.R., Sato, M., Sunka, P., Hoffmann, M.R. and Chang, J.-S. (2006) Electrohydraulic Discharge and Nonthermal Plasma for Water Treatment. Industrial and Engineering Chemistry Research, 45, 882-905. https://doi.org/10.1021/ie050981u 
[2] Gao, J.Z., Pu, L.M., Yang, W., Yu, J. and Li, Y. (2004) Oxidative Degradation of Nitrophenols in Aqueous Solution Induced by Plasma with Submersed Glow Discharge Electrolysis. Plasma Process and Polymers, 1, 171-176. https://doi.org/10.1002/ppap.200400012

[3] Servais, P., Billen, G. and Hascoet, M.C. (1987) Determination of the Biodegradable Fraction of Dissolved Organic Matter in Waters. Water Research, 21, 445-450.

[4] Qu, R.-J., Feng, M.-G., Wang, X.-G. Huang, Q.-G., Lu, J.-H., Wang, L.-S. and Wang, Z.-Y. (2015) Rapid Removal of Tetrabromobisphenol A by Ozonation in Water: Oxidation Products, Reaction Pathways and Toxicity Assessment. PLoS ONE, 10, $1-17$.

[5] Wang, X.-Y., Zhou, M.H. and Jin, X.L. (2012) Application of Glow Discharge Plasma for Wastewater Treatment. Electrochimica Acta, 83, 501-512.

https://doi.org/10.1016/j.electacta.2012.06.131

[6] Gong, J.Y., Wang, J., Xie, W.J. and Cai, W.-M. (2008) Enhanced Degradation of Aqueous Methyl Orange by Contact Glow Discharge Electrolysis Using $\mathrm{Fe}^{2+}$ as Catalyst. Journal of Applied Electrochemistry, 38, 1749-1755.

https://doi.org/10.1007/s10800-008-9626-Z

[7] Tang, Q.-O., Jiang, W.J., Zhang, Y., Wei, W.Y. and Lim, T.M. (2009) Degradation of Azo Dye Acid Red 88 by Gas Phase Dielectric Barrier Discharges. Plasma Chemistry and Plasma Processing, 29, 291-305. https://doi.org/10.1007/s11090-009-9181-3

[8] Huang, F.-M., Chen, L., Wang, H.-L., Feng, T.-Z. and Yan, Z.-C. (2012) Degradation of methyl Orange by Atmospheric DBD Plasma: Analysis of the Degradation Effects and Degradation Path. Journal of Electrostatistics, 70, 43-47.

https://doi.org/10.1016/j.elstat.2011.10.001

[9] Huang, F.M., Chan, L., Wang, H.L. and Yan, Z.C. (2010) Analysis of the Degradation Mechanism of Methylene Blue by Atmospheric Pressure Dielectric Barrier Discharge Plasma. Chemical Engineering Journal, 162, 250-256. https://doi.org/10.1016/j.cej.2010.05.041

[10] Xue, J., Chen, L. and Wang, H.-L. (2008) Degradation Mechanism of Alizarin Red in Hybrid Gas-Liquid Phase Dielectric Barrier Discharge Plasmas: Experimental and Theoretical Examination. Chemical Engineering Journal, 138, 120-127. https://doi.org/10.1016/j.cej.2007.05.055

[11] Lukes, P. and Locke, B.R. (2005) Degradation of Substituted Phenols in a Hybrid Gas-Liquid Electrical Discharge Reactor. Industrial and Engineering Chemistry Research, 44, 2921-2930. https://doi.org/10.1021/ie0491342

[12] Katayama-Hirayama, K., Toda, N., Tauchi, A., Fujioka, A., Akitsu, T., Kaneko, H. and Hirayama K. (2014) Degradation of Dibromophenols by UV Irradiation. Journal of Environmental Sciences, 26, 184 188,

[13] Kojima, S., Katayama-Hirayama, K. and Akitsu, T. (2016) Degradation of Aqueous 2,6-Dibromophenol Solution by In-Liquid Barrier Microplasma. World Journal of Engineering and Technology, 4, 423-432. https://doi.org/10.4236/wjet.2016.43042

[14] Ji, Y.-F., Li, J.-H., Lu, J.-H., Shi, Y.-Y., Zhou, L., Yang, Y., Yang, P.-Z., Wang, L., Ferronato, C. and Chovelon, J.M. (2018) Rethinking Sulfate Redical-Based Oxidation of Nitrophenols: Formation of Toxic Poly-Nitrophenols, Nitrated Bisphenols and Diphenyl Ethers. Journal of Hazardous Materials, 361, 152-161. https://doi.org/10.1016/j.jhazmat.2018.08.083

[15] Kang, S.-F., Wang, T.-H. and Lin, Y.-H. (2008) Decolorization and Degradation of 2,4-Dinitrophenol by Fenton's Reagent. Journal of Environmental Science and Health, Part A, 34, 935-950. https://doi.org/10.1080/10934529909376874 
[16] Fukui, K., Yonezawa, T. and Shingu, H. (1952) A Molecular Orbital Theory of Reactivity in Aromatic Hydrocarbons. The Journal of Chemical Physics, 20, 722-725.

[17] Fleming, I. (1978) Frontier Orbitals and Organic Chemical Reactions. Wiley, London, 24-109.

[18] BiomedicalCAChe 6.0 Users Guide, 2003, Fujitsu.

[19] Somekawa, K. (2013) Molecular Orbital Calculation of Organic Molecules and the Application. Kyushu University Press, Fukuoka.

[20] PUBCHEM.

https://pubchem.ncbi.nlm.nih.gov/compound/3_4-dinitrophenol\#section=2D-Struc ture

\section{Appendix}

Dinitrophenol has several types of different structure is available [20].<smiles>O=[N+]([O-])c1ccc([N+](=O)[O-])c(O)c1</smiles>

(a)

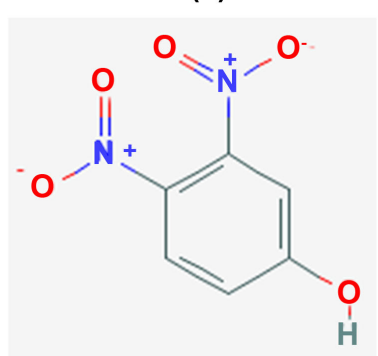

(c)

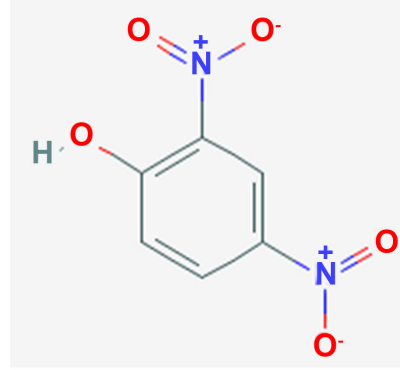

(b) 